\title{
CO-MORBIDITIES IN CHILDREN WITH CEREBRAL PALSY UNDERGOING EARLY SPINE FUSION FOR SCOLIOSIS
}

\author{
Prakash Sitoula and Freeman Miller
}

\begin{abstract}
Introduction: Children with Cerebral Palsy (CP) may have multisystem involvement the occurrence of which increases with severity of involvement. Scoliosis is also found to be more prevalent in severely involved children with CP.

Aims: This study aimed to describe co-morbidities in children with $\mathrm{CP}$ undergoing early spine fusion for scoliosis.

Methods: A retrospective review of patients with CP Scoliosis between 1989 and 206 who were $<10$ years at spine fusion was done. Demographics, mental status, pre-operative weight and height and body-mass index (BMI), curve characteristics, geographic pattern of involvement and GMFCS level were reported. Co-morbidities were broadly categorized as those involving central nervous system, gastrointestinal system and respiratory system.

Results: 42 patients (24 male and 18 female) with mean age of $8.1 \pm 1.6$ years at surgery were identified. The mean preoperative weight, height, and BMI were $22 \pm 6.8$ kilograms, $115 \pm 11.8$ centimeters and $16 \pm 3.7$ respectively. All patients were mentally retarded and quadriplegic. GMFCS level was V in 40 patients and IV in 2 patients. The mean Cobb angle was $83.4^{\circ} \pm 18.3^{\circ}$ and pelvic tilt was $18^{\circ} \pm 10^{\circ}$. Seizure disorder and GER were present in $98 \%$ and $69 \%$ of patients respectively. $88 \%$ patients had gastrostomy-tube for feeding. $31 \%$ patients were tracheostomized; $46 \%$ of them were ventilator dependent. Asthma/ reactive airway disease, restrictive lung disease and obstructive respiratory disease/ sleep apnea were present in $29 \%$, $17 \%$ and $5 \%$ of patients respectively. $19 \%$ patients had recurrent aspiration pneumonitis.
\end{abstract}

Conclusion: Our study showed that children with $\mathrm{CP}$ Scoliosis progressing to surgical range before 10 years of age are severely involved with co-morbidities encompassing multiple organsystems.

Key words: Cerebral Palsy, Scoliosis, Co-morbidities, Spine fusion

\section{Introduction}

Cerebral Palsy (CP) is caused by an ischemic insult to immature brain. In this condition, the primary lesion remains static, however the motor manifestations evolve with time due to spasticity $(1,2)$. Scoliosis is found to be more common in non-ambulatory spastic quadriplegic children with $\mathrm{CP}$ with reported prevalence of up to $75 \%(3-6)$.

Multisystem involvement is common in children with $\mathrm{CP}$ and the prevalence increases with severity of involvement $(2,7,8)$. Seizure is commonly associated with $\mathrm{CP}(2,9)$. 
Occurrence of oral-motor dysfunction has been reported in this patient population leading to poor nutrition and growth $(8,10)$. Assistive feeding in the form of gastrostomytube or nasogastric-tube is warranted. Respiratory system involvement is also common in severely involved children with $\mathrm{CP}(11,12)$.

Larger curves are often associated with high pelvic obliquity and need surgery. The aim of surgical treatment in this patient population is to improve sitting or standing balance and facilitate nursing care (13). Presence of comorbidities often complicates treatment process. The literature is scarce on treatment of scoliosis in children with CP less than 10 year of age (14) and there are no studies describing co-morbidities in this patient population. The aim of this study was to describe co-morbidities in children with $\mathrm{CP}$ undergoing spine fusion before 10 years of age for scoliosis.

\section{Methods}

After an institutional review board approval (Nemours/ A. I. duPont Hospital for Children, Delaware, USA), a review of patients with cerebral palsy undergoing early spine fusion for scoliosis between 1989 and 2006 was done. The inclusion criteria were: (1) patients with $\mathrm{CP}$ with scoliosis and (2) age less than 10 years at spine fusion.

The following parameters were recorded after appraisal of the medical records: age at surgery, gender, mental status, mobility, Gross Motor Classification System (GMFCS) level and type of $\mathrm{CP}$ based on geographic pattern of involvement (quadriplegic/diplegic/hemiplegic).

Preoperative height and weight were also recorded and body mass index was calculated from these parameters. Height was measured by arm-board measurement technique described by Miller and Koreska (15).
In this patient population, scoliotic curves of $60^{\circ}$ or more were managed surgically. The Cobb angle for scoliosis, thoracic kyphosis and lumbar lordosis were measured by the Cobb method (16).

The co-morbidities were broadly classified as those affecting: (1) central nervous system (Seizure disorder); (2) respiratory system (reactive airway disease and asthma; restrictive airway disease; recurrent aspiration pneumonitis; obstructive airway disease; tracheostomy and need for ventilator); (3) gastrointestinal system [gastrostomy-feeding tube for nutrition; gastroesophageal reflux (GER) with or without the need for Nissen fundoplication].

\section{Statistical analysis}

Data was examined for normality prior to hypothesis testing. Mean and SD were used for summary statistics for continuous variables and frequency and percentages were used for categorical variables. STATA version 12.0 (STATACorp, College Station, TX) was used for data analysis.

\section{Results}

Forty-two patients, male $24(57 \%)$ and female $18(43 \%)$, met the inclusion criteria and formed the cohort for this study. The mean age at surgery was $8.1 \pm 1.6$ years (range, 4.4 9.9). The mean preoperative body weight was $22 \pm 6.8$ kilograms (range, 10 - 37) and height was $115 \pm 11.8$ centimeters (range, $92-147$ ). The mean body mass index was $16 \pm 3.7$ (range, $10-27$ ) (Table 1).

All patients in this series were quadriplegic with $95 \%$ of them being bedridden and completely dependent for all their activities of daily living. Remaining 5\% were capable of transfer from wheelchair with support. Similarly, all patients were mentally retarded; 
95\% of patients had severe mental retardation (MR) while remaining $5 \%$ had moderate MR.

Table 1. Demographics

\begin{tabular}{|c|c|c|c|}
\hline \multicolumn{2}{|l|}{ Variable } & \multicolumn{2}{|c|}{ Frequency } \\
\hline \multicolumn{4}{|l|}{ Gender } \\
\hline \multicolumn{2}{|l|}{ Male } & & 24 \\
\hline \multicolumn{2}{|l|}{ Female } & & 18 \\
\hline \multicolumn{4}{|l|}{ Geographic pattern } \\
\hline \multicolumn{2}{|c|}{ Quadriplegia } & & 42 \\
\hline \multicolumn{4}{|l|}{ Ambulation } \\
\hline \multicolumn{2}{|l|}{ Bedridden } & & 40 \\
\hline \multicolumn{2}{|l|}{ Sitter } & & 2 \\
\hline \multicolumn{4}{|l|}{ Mental Retardation } \\
\hline \multicolumn{2}{|l|}{ Severe } & & 40 \\
\hline \multirow{2}{*}{\multicolumn{4}{|c|}{$\begin{array}{c}\text { Moderate } \\
\text { Age at Surgerv (vear }\end{array}$}} \\
\hline & & & \\
\hline \multicolumn{4}{|l|}{ Weight $(\mathrm{Kg})$} \\
\hline \multicolumn{4}{|l|}{ Height $(\mathrm{cm})$} \\
\hline \multicolumn{4}{|l|}{ BMI } \\
\hline \multicolumn{4}{|c|}{$\begin{array}{l}\text { The mean Cobb angle was } 83.4^{\circ} \pm 18.3^{\circ} \\
\left(\text { range, } 50^{\circ}-118^{\circ}\right) \text {, pelvic tilt was } 18^{\circ} \pm 10^{\circ} \\
\left(\text { range, } 2^{\circ}-45^{\circ}\right) \text {, thoracic kyphosis was } 53.4^{\circ} \\
\pm 28.4^{\circ}\left(-3^{\circ}-113^{\circ} \text { ) and lumbar lordosis was }\right. \\
32.3^{\circ} \pm 33^{\circ}\left(\text { range, }-64^{\circ}-100^{\circ} \text { ) (Table } 2 \text { ). }\right.\end{array}$} \\
\hline \multicolumn{4}{|c|}{ Table 2. Curve Characteristics } \\
\hline Variable & Mean & SD & Range \\
\hline Cobb angle & 83.4 & 18.3 & $50-118$ \\
\hline Pelvic tilt & 18 & 10 & $2-45$ \\
\hline Thoracic kyphosis & 53.4 & 28.4 & $-3-113$ \\
\hline Lumbar Lordosis & 32.3 & 33 & $-64-100$ \\
\hline
\end{tabular}

All patients but one had at least single comorbidity (Table 4). Seizure disorder was present in $98 \%$ of the patients. Eighty-eight percent patients had gastrostomy-tube for feeding. GER was present in $69 \%$ of patients out of which $65.5 \%$ had Nissen Fundoplication. Thirty-one percent patients had tracheostomy tube for breathing; $46 \%$ of these were ventilator dependent. Respiratory system involvement included obstructive, restrictive and reactive airway diseases. Obstructive respiratory disease/ sleep apnea was present in 5\% of patients. Restrictive lung disease and asthma/ reactive airway

Percentage

57

43

100

95

5

95

5

$\begin{array}{ccc}8.1 & 1.6 & 4.4-9.9 \\ 22 & 6.8 & 10-37 \\ 115 & 11.8 & 92-147 \\ 16 & 3.7 & 10-27\end{array}$

disease was seen in $17 \%$ and $29 \%$ of patients respectively. Nineteen percent patients had recurrent aspiration pneumonitis (Table 3 ).

Table 3. Co-Morbidities

\begin{tabular}{|c|c|c|}
\hline Variable & Frequency & Percentage \\
\hline \multicolumn{3}{|l|}{ Gastrostomy-tube feeding } \\
\hline Yes & 37 & 88 \\
\hline No & 5 & 12 \\
\hline Gastroesophageal reflux & 29 & 69 \\
\hline Nissen Fundoplication (NF) & 19 & 65.5 \\
\hline No NF & 10 & 35.5 \\
\hline \multicolumn{3}{|l|}{ Seizure disorder } \\
\hline Yes & 41 & 98 \\
\hline No & 1 & 2 \\
\hline Tracheostomy & 13 & 31 \\
\hline Ventilator dependent & 6 & 46 \\
\hline Non-ventilator dependent & 7 & 54 \\
\hline \multicolumn{3}{|c|}{ Obstructive Respiratory Disease/Sleep apnea } \\
\hline Yes & 2 & 5 \\
\hline No & 40 & 95 \\
\hline \multicolumn{3}{|l|}{ Restrictive Lung Disease } \\
\hline Yes & 7 & 17 \\
\hline No & 35 & 83 \\
\hline \multicolumn{3}{|l|}{$\begin{array}{l}\text { Asthma/ Reactive Airway } \\
\text { Disease }\end{array}$} \\
\hline Yes & 12 & 29 \\
\hline No & 30 & 71 \\
\hline \multicolumn{3}{|l|}{$\begin{array}{l}\text { Recurrent Aspiration } \\
\text { Pneumonitis }\end{array}$} \\
\hline Yes & 8 & 19 \\
\hline
\end{tabular}


No 34 81

Table 4. Number of Co-morbidities

\begin{tabular}{ccc}
\hline $\begin{array}{c}\text { Number of Co- } \\
\text { morbidities }\end{array}$ & $\begin{array}{c}\text { Frequen } \\
\text { cy }\end{array}$ & $\begin{array}{c}\text { Percenta } \\
\text { ge }\end{array}$ \\
\hline 0 & 1 & 2.4 \\
1 & 1 & 2.4 \\
2 & 7 & 16.7 \\
3 & 13 & 31 \\
4 & 7 & 16.7 \\
5 & 11 & 26.2 \\
6 & 2 & 4.8 \\
\hline
\end{tabular}

\section{Discussion}

Prevalence of scoliosis in CP patients increases with severity of involvement with ambulation potential being a significant predictor for development these curves $(4,5$, 17). We found children who develop surgical curve early in their life often have number of co-morbidities.

Ninety-five percent of patients in the present series were bedridden with complete dependence for activities of daily living while remaining $5 \%$ were capable of wheelchair transfer. In a series of institutionalized patients with $\mathrm{CP}$, Saito et al(6) reported development of severe scoliosis in $67 \%$ of patients with total body involvement and $100 \%$ of patients who were bedridden. All patients in the current series were mentally retarded: $95 \%$ of the cohort had severe MR and remaining 5\% had moderate MR. Kalen et al(13) reported severe $\mathrm{MR}$ in all 14 institutionalized $\mathrm{CP}$ adult patients with curves $>45^{\circ}$ as opposed to $74 \%(n=42)$ of those with curves $<45^{\circ}$.

Majority of patients in the current series had poor nutritional status as depicted by low BMI (mean BMI=16). Eighty-eight percent patients needed gastrostomy-tube for feeding. In a prospective longitudinal study by Sullivan et al(8) to show the effect of gastrostomy feeding in children with $\mathrm{CP}$, two- thirds of patients (43 of 57) had spastic quadriplegia. The oral-motor dysfunction is found to be more prevalent in severely involved children with CP needing feeding support. This study showed significant improvement in nutritional status of the children with $\mathrm{CP}$ following enteral feeding as indicated by body weight, limb growth and subcutaneous fat deposition.

Ninety-eight percent of patients in the present series had seizure disorder. Venkateswaran and Shevell(2) described seizure in $47 \%$ of their cohort with CP. Similarly, in a series of 323 patients with $\mathrm{CP}$, Hadjipanayis et al(9) reported this condition in $41.8 \%$ of overall cohort and in about $50 \%$ of patients with spastic tetraplegia. Higher incidence of seizure disorder in the current series may have been due to greater severity of involvement of patients. However, fewer numbers of patients leading to sparse data bias cannot be negated. Gastroesophageal reflux was observed in 69\% of cohort in the present series. The reported incidence of GER in children with CP ranges from $26 \%$ to $91 \%(18,19)$. This condition has been found to be associated with number of pulmonary diseases in children. In a series of otherwise normal children with GER, Euler et al(11) reported recurrent pneumonitis in $94 \%$. In a similar cohort of patients with steroid dependent asthma, Shapiro et al(12) demonstrated GER in $43 \%$ of patients. In the present series, recurrent aspiration pneumonitis and asthma/ reactive airway disease were documented in $19 \%$ and $29 \%$ patients respectively.

This study has number of limitations. This is a retrospective study with its inherent biases. There may have been sparse data bias due to fewer numbers of patients as this study deals with rare surgical entity in pediatric orthopedics.

\section{Conclusion}

Our study showed that children with $\mathrm{CP}$ needing surgery for scoliosis before 10 years 
of age are severely involved with comorbidities encompassing multiple organsystems. These children need multidisciplinary team approach for management of their medical conditions before and after surgery.

\section{References}

1. Badawi N, Watson L, Petterson B, Blair E, Slee J, Haan E, et al. What constitutes cerebral palsy? Dev Med Child Neurol. 1998;40(8):520-7.

2. Venkateswaran S, Shevell MI. Comorbidities and clinical determinants of outcome in children with spastic quadriplegic cerebral palsy. Dev Med Child Neurol. 2008;50(3):216-22.

3. Edebol-Tysk K. Epidemiology of spastic tetraplegic cerebral palsy in Sweden. I. Impairments and disabilities. Neuropediatrics. 1989;20(1):41-5

4. Persson-Bunke M, Hagglund G, LaugePedersen H, Wagner P, Westbom L. Scoliosis in a total population of children with cerebral palsy. Spine. 2012;37(12):E708-13.

5. Robson P. The prevalence of scoliosis in adolescents and young adults with cerebral palsy. Dev Med Child Neurol. 1968;10(4):447-52.

6. Saito N, Ebara S, Ohotsuka K, Kumeta H, Takaoka K. Natural history of scoliosis in spastic cerebral palsy. Lancet. 1998;351(9117):1687-92.

7. Shevell MI, Dagenais L, Hall N. Comorbidities in cerebral palsy and their relationship to neurologic subtype and GMFCS level. Neurology. 2009;72(24):2090-

8. Sullivan PB, Juszczak E, Bachlet AM, Lambert B, Vernon-Roberts A, Grant HW, et al. Gastrostomy tube feeding in children with cerebral palsy: a prospective, longitudinal study. Dev Med Child Neurol. 2005;47(2):77-85.

9. Hadjipanayis A, Hadjichristodoulou C, Youroukos S. Epilepsy in patients with cerebral palsy. Dev Med Child Neurol. 1997;39(10):659-63.
10. Dahl M, Thommessen M, Rasmussen $M$, Selberg T. Feeding and nutritional characteristics in children with moderate or severe cerebral palsy. Acta paediatrica (Oslo, Norway : 1992). 1996;85(6):697-701.

11. Euler AR, Byrne WJ, Ament ME, Fonkalsrud EW, Strobel CT, Siegel SC, et al. Recurrent pulmonary disease in children: a complication of gastroesophageal reflux. Pediatrics. 1979;63(1):47-51.

12. Shapiro GG C, DL, Pierson WE, et al. Gastroesophagealreflux in asthmatic children. abstractedI Allergy Clin Immunol. 1978;61(137).

13. Kalen V, Conklin MM, Sherman FC. Untreated scoliosis in severe cerebral palsy. J Pediatr Orthop. 1992;12(3):337-40.

14. McElroy MJ, Sponseller PD, Dattilo JR, Thompson GH, Akbarnia BA, Shah SA, et al. Growing rods for the treatment of scoliosis in children with cerebral palsy: a critical assessment. Spine. 2012;37(24):E1504-10.

15. Miller F, Koreska J. Height measurement of patients with neuromuscular disease and contractures. Dev Med Child Neurol. 1992;34(1):55-60.

16. Cobb JR. Outline for the study of scoliosis. In: American Academy of Orthopaedic Surgeons, ed Instructional Course Lectures. Ann Arbor, MI: JW Edwards; 1948. p. 261-75.

17. Madigan RR, Wallace SL. Scoliosis in the institutionalized cerebral palsy population. Spine. 1981;6(6):583-90.

18. Drvaric DM, Roberts JM, Burke SW, King AG, Falterman K. Gastroesophageal evaluation in totally involved cerebral palsy patients. J Pediatr Orthop. 1987;7(2):187-90.

19. Spiroglou K, Xinias I, Karatzas N, Karatza E, Arsos G, Panteliadis C. Gastric emptying in children with cerebral palsy and gastroesophageal reflux. Pediatr Neurol. 2004;31(3):177-82.

Corresponding Author: Dr. Prakash Sitoula, Department of Orthopedics Nobel Medical College Teaching Hospital Kanchanbari, Biratnagar Nepal. Phone: 00977-9852027322 Email: prakashsitoula@gmail.com 